\title{
Effect of Various Lower Extremity Exercises Using the Swiss Ball while Standing on Balance, Muscle Strength, Gait and Fall Efficacy in Stroke Patients: A Pilot Study
}

\author{
Yun-Jeong Lim, Soon-Hee Kang \\ Department of Physical Therapy, Korea National University of Transportation, Chungju, Republic of Korea
}

\begin{abstract}
Purpose: This study examined whether various lower extremity exercises using a Swiss ball in the standing position could improve balance, muscle strength, gait, and fall efficacy in stroke patients.

Methods: Twenty-one stroke patients were randomly divided into three groups, each with seven participants. For four weeks, experimental group 1 performed various lower extremity exercises using a Swiss ball, while experimental group 2 executed the same exercises without a Swiss ball, and the control group underwent general physical therapy. The subjects' knee extensor muscle strength, balance, gait, and fall efficacy were evaluated before and after the intervention using portable muscle strength measurement, the Berg Balance Scale (BBS), G-walk, and the Korean Falls Efficacy Scale (K-FES).

Results: Knee extensor strength increased significantly in all three groups after the intervention; in particular, a significant increase was seen in experimental groups 1 and 2 compared to the control group. Moreover, all three groups had significantly better BBS scores and higher cadence after the intervention; notably, experimental group 1 had better scores and increased cadence than the control group. Additionally, gait speed was significantly increased in the experimental group 1 than in the control group. The step length of the non-affected leg was also significantly higher in the same group. The K-FES score improved significantly in all three groups, but there was no significant difference between the groups.
\end{abstract}

Conclusion: This study suggests that lower extremity exercises with or without a Swiss ball could be effective interventions to improve muscle strength, balance, gait, and fall efficacy in stroke patients.

Keywords: Stroke, Swiss ball, Muscle Strength, Balance, Gait, Fall efficacy

\section{서 론}

뇌졸중은 만성 장애와 사망을 유발할 수 있는 중요한 뇌혈관 질환 이다.' 대뇌 병변의 위치와 범위에 따라 손상 정도와 회복 및 뇌졸중 후유증은 다르지만, ${ }^{2}$ 가장 빈번한 운동 장애는 편마비이다. 뇌졸중 환자들은 마비측의 감각소실과 근력 약화로 인하여 신체의 분절을 정렬하고 자세를 조절하는 균형능력이 제한될 뿐만 아니라 낙상위험 도의 증가와 균형능력의 감소와 불충분한 자세조절능력으로 인하여 독립적인 일상생활수행능력 및 보행의 어려움이 발생된다. ${ }^{3}$ 뇌졸중 환자는 보행 시 한 다리 지지기에서 무릎 폄근 및 굽힘근의 약화 및 경직으로 인해 젖힌 무릎(genu recurvatum)이 나타나고, ${ }^{4}$ 디딤기 단계 에서 불충분한 체중부하가 비대칭 보행을 유발한다.5,6 또한 뇌졸중
환자는 증가된 양다리지지기(double limb support), 활보시간(stride time), 보행시간(step time)이 나타나며, 감소된 보행률(cadence), 한걸음 거리(stride length), 한발짝거리(step length), 한다리지지기(single limb support)가 나타나는 병적보행 형태를 보인다. 균형은 기저면 내에 신 체의 중심을 유지하는 능력으로 보행 능력과 강한 상관관계가 있고, ${ }^{8}$ 일상생활에서 기능적인 동작을 수행하는데 필수적인 요인이다. ${ }^{9}$ 따 라서 뇌졸중 환자의 기능적 능력 회복을 위해서는 정적 및 동적 균형 을 향상시키는 것이 중요하다. ${ }^{10}$

뇌졸중 환자들은 비대칭적인 체중분포, 체중이동 능력의 손상, 자 세의 동요로 인한 반응시간의 지연 등의 균형능력의 감소에 의해 보 행 시 방향 전환이나 장애물을 피하거나 건너는 것에 대한 어려움이 있고, 이로 인해 낙상의 위험도가 증가하게 된다." 낙상에 대한 두려
Received Jul 21, 2021 Revised Aug 29, 2021

Accepted Aug 29, 2021

Corresponding author Soon-Hee Kang

E-mail shkang@ut.ac.kr
Copylight (C)2021 The Korean Society of Physical Therapy

This is an Open Access article distribute under the terms of the Creative Commons Attribution Non-commercial License (https:// creativecommons.org/license/by-nc/4.o.) which permits unrestricted non-commercial use, distribution, and reproduction in any medium, provided the original work is properly cited. 
움이 있는 뇌졸중 환자의 심리적인 장벽이 좌절, 우울, 불안과 같은 정서적 고통에 의해 되며 신체의 기능 저하, 균형과 이동능력의 악화 등의 영향으로 낙상 빈도수의 증가와 일상생활에서의 삶의 질 저하 등이 나타난다. ${ }^{12}$ 이와 같은 뇌졸중 환자들의 뇌졸중 후 문제점을 개 선하여 그들의 신체기능의 향상과 일상생활로의 복귀를 위해 재활 치료 방법이 다방면으로 연구되고 있다.

일상생활을 영위하는 데 있어 선 자세는 신체의 중심이 높아져 가 동성 증진 등을 위한 필수 조건이고, 일어서기, 이동하기, 걷기, 방향 바꾸기, 계단 오르기 등의 활동을 위하여 중요하다. ${ }^{13}$ 선 자세와 같은 신체중심이 높은 항중력 자세는 뇌졸중 환자에게 치료적으로 효과 적이다. ${ }^{14}$ 기저면의 넓이 감소에 따른 신체중심의 변화는 근육의 동원 과 활성도를 증가시킨다. 신체중심이 높은 선 자세에서 불안정한 훈 련은 수의적인 움직임을 할 때 자세조절이 복잡해지고, 많은 근육들 을 사용하며, 체간의 항중력근이 반응하여 높은 근 활성을 보여 자세 동요에 따른 자세 안정을 유지할 수 있도록 한다. ${ }^{15}$ 이러한 선 자세에 서의 치료를 통한 효과를 보기 위한 운동프로그램 중 균형감각과 보 행능력을 회복시키고, 체중부하를 통한 하지 기능을 강화시키기 위 해 벽에 기대어 서는 훈련을 기대기 훈련 프로그램이라고 한다. 이러 한 훈련은 매일 기립자세를 유지함으로써 마비된 하지의 근육위축 을 감소시키고 균형감각과 자세조절력을 회복시키는데 긍정적인 효 과가 있다. ${ }^{16}$ 또한 지지된 기립의 장점으로는 수축된 근육 스트레칭, 경련 감소, 근육 강화, 항 중력 근육 활동 자극 등이 있다. 앞서 언급한 이점은 척수 손상, 다발성 경화증, 뇌졸중 및 외상성 뇌 손상이 있는 사람들에게 30 분 동안 규칙적으로 서 있으면 관찰될 수 있음을 나타 낸다.1718

최근 스위스볼 운동의 체간 안정화 효과로 뇌졸중 환자들의 몸통 및 상지의 기능 개선, ${ }^{1921}$ 요통환자들의 통증 감소 22 및 지역사회 노인 의 균형 및 보행 3 에 긍정적인 중재로 보고되고 있다. 스위스볼 운동 은 저충격 운동으로 남녀노소 누구나 다른 운동기구보다 거부감 없 이 재미와 흥미 면에서도 뛰어난 운동이며, 24,25 신체의 반사신경, 지각 능력, 균형감각, 고유수용성 감각이 몸을 공에 기댈 때 증가되어 종합 적으로 신체를 강화시키고, ${ }^{25}$ 몸통근을 활성화 ${ }^{20}$ 시키는 장점을 가지 고 있다.

선행연구에서 스위스볼 운동은 바로 누운 자세나 앉은 자세에서 진행되었으나, ${ }^{192,23,26}$ 선 자세에서 수행하는 신체기능에 대한 스위스볼 운동의 효과에 대한 연구는 아직 충분치 않고, 뇌졸중 환자에게 스 위스볼을 이용한 기대기 훈련이 하지 근력과 균형, 보행 및 낙상효능 감에 미치는 영향 등에 대한 내용을 보고하는 연구는 부족한 실정이 기에 추가적인 연구가 필요하다. 따라서 본 연구에서는 선 자세에서 스위스볼을 이용한 다양한 하지 운동이 뇌졸중 환자들의 근력, 균형, 보행 및 낙상효능감에 어떤 영향을 미치는 지를 알아보고자 하였다.

\section{연구 방법}

\section{1. 연구대상}

본 연구의 대상자는 C시 P병원에서 입원치료를 받고 있는 뇌졸중 으로 인한 편마비로 진단받은 환자로서, 보호자 또는 본인의 실험 참 가 동의를 얻어 선정하였으며, 총 21 명의 대상자들을 실험군 $1(n=7)$ 과 실험군 $2(\mathrm{n}=7)$ 및 대조군 $(\mathrm{n}=7)$ 에 무작위 배정하였다. 본 연구 대상 자의 선정기준은 첫째, 뇌졸중 진단을 받은 지 1 개월 이상 6 개월 이하 이면서 치료사의 지시를 이해하고 과제 수행이 가능한 자, 둘째, 한국 형 간이 정신 상태 검사(K-MMSE)에서 24점 이상인 자, 셋째, 연구에 영향을 주는 전정기관이나 시야결손의 문제가 없는 자, 넷째, 연구에 영향을 주는 정형외과적 질환이 없는 자, 다섯째, 보행 보조기 유무 에 상관없이 독립적으로 걸을 수 있는 환자 등이었다. 본 연구에서 양 측마비, 소뇌질환 또는 시야 결손이 있는 자 또는 의사소통이 불가능 한자는 제외하였다.

\section{2. 측정방법 및 도구}

1) 근력 평가

근력을 평가하기 위하여 휴대용 근력 측정계(MicroFET2, Hoggan Health Industries, UT)를 사용하여 대상자들의 마비측 무릎 관절 폄 근의 등척성 근력을 측정하였다. 이는 사용이 간단하고 크기가 작은 장점이 있으며, 선행연구에서 이 검사에 대한 검사자내 신뢰도는 ICC 0.86-0.94로 높은 신뢰도를 보였다.27,28 본 연구에서는 대상자들에게 앉은 자세에서 무릎을 펴게 함으로써 넙다리네갈래근의 근력을 검 사하였고, 압력판은 마비측 발목 앞부분에 위치하여 측정하였다.28

\section{2) 균형 평가}

균형을 평가하기 위하여 한국판 버그 균형 척도(Berg balance scale, $\mathrm{BBS})$ 를 사용하였다. 버그 균형 척도는 일상생활동작을 응용한 항목 으로 앉기, 서기 자세, 자세 변화의 3 대 영역, 총 14 항목으로 구성되어 있고, 총점은 56 점이며 각 항목별 0 점에서 4점으로 이루어진다. ${ }^{29}$ 버그 균형 척도는 점수가 높을수록 균형능력이 우수함을 의미한다. 뇌졸 중 환자를 대상으로 버그 균형 척도 검사의 검사자 내 신뢰도와 측정 자간 신뢰도는 각각 $r=0.98$ 와 $r=0.97$ 로 높은 신뢰도를 가지고 있다. ${ }^{30}$

\section{3) 보행 평가}

보행을 평가하기 위하여 보행분석 장비인 G-walk (BTS G-walk ${ }^{\circledR}$, BTS Bioengineering, Garbagnate Milanese, Italy)를 사용하였다. G-walk 는 시공간 보행 특성을 측정하는데 적합한 측정도구이다. 3 축 가속 도계, 센서 및 3 축 자이로스코프가 장착된 무선 시스템 $\mathrm{G}$ 센서와 무 선 소프트웨어 프로그램을 사용하여 측정할 수 있다. G-walk를 이용 
한 보행 평가는 허리(L5) 영역에 무선 G 센서가 부착된 벨트를 장착하 고, $8 \mathrm{~m}$ 를 걸어 측정하였다. G-walk는 급내 상관계수(ICC)가 0.84-0.99 로 높은 신뢰도를 가진 연구도구이다. ${ }^{31}$ 본 연구에서는 이 장비로 보 행률(cadence), 보행속도(speed), 비마비측 한발짝길이(step length)의 보행 변수를 측정하였다.

\section{4) 낙상효능감 평가}

스웨덴판 낙상효능감 척도(Fall Efficacy Scale-Swedish version, FESS)를 번안하여 만든 한국판 낙상효능감 척도(Fall Efficacy Scale-Korea version, FES-K)를 사용하였다. ${ }^{32}$ 이 도구는 일상생활활동(ADL)을 나 타내는 13 개 항목을 수행한다는 가정하에 직접 평가하는 것으로, 0-10점의 11 점 척도로 평가한다. 0 점이 전혀 두렵지 않음, 5 점이 어느 정도 자신이 있는 경우, 0 점이 매우 두려운 경우로, 숫자가 클수록 낙 상에 대한 두려움이 크고 낙상관련 자기효능감이 낮은 것을 의미한 다. 내적일치도는 0.959 , 기준 타당도는 $0.41-0.54$ 이다. ${ }^{33}$

\section{3. 실험 절차}

본 연구에 동의하고 대상자의 선정기준에 합당한 총 21 명의 뇌졸 중 환자들을 선정한 후, 휴대용 근력 측정계, $\mathrm{BBS}, \mathrm{G}$-walk, K-FES 측정 도구들을 사용하여 근력, 균형, 보행 및 낙상효능감을 평가하였다. 이 후 대상자들을 실험군 1 , 실험군2 및 대조군의 세 집단에 각 7명씩 무 작위 배정한 다음에, 4 주간 각 집단별 스위스볼을 이용한 하지 운동 과 일반적인 물리치료(실험군1), 스위스볼을 사용하지 않고 동일한 운동과 일반적인 물리치료(실험군2) 및 일반적인 물리치료(대조군) 를 적용하였고, 중재 후 동일한 측정도구들을 사용하여 대상자들의 근력, 균형, 보행 및 낙상효능감을 평가하였다.

\section{4. 중재 방법}

\section{1) 스위스볼을 이용한 하지 운동}

본 연구에서는 실험군1의 대상자들에게 스위스볼 운동을 4 주간 주당 5 회, 회기당 30 분간 적용하였다. 스위스볼 운동은 기대기 훈련, ${ }^{16}$ 스텝박스 오르고 내리기, ${ }^{34}$ 벽-스쿼트 운동 ${ }^{35}$ 의 하지기능, 체중부하 이
동 및 보행에 긍정적 효과를 보고한 선행연구에 기초하여 스위스볼 에 등을 대고 서기, 스위스볼에 등을 대고 발판(step box)에 양발 교대 로 올리고 내리기, 스위스볼에 등을 대고 스쿼트(squat) 하기, 스위스 볼에 마비측을 대고 서기 등 네 가지 운동으로 구성되었고, 훈련 3-4 주 차에는 각 운동의 난이도를 높여서 진행 실시하였다. 스위스 볼을 이용한 하지 운동은 Table 1과 같다.

\section{2) 스위스 볼을 이용하지 않은 운동}

본 연구에서는 실험군2의 대상자들에게 스위스볼 대신에 벽을 이 용하여 실험군 1 에게 적용된 동일한 운동을 4 주간 주당 5 회, 회기당 30 분간 적용하였다.

\section{3) 일반적인 물리치료}

일반적인 물리치료는 실험군1, 실험군2에게는 4 주간, 주당 5 회, 회 기당 30 분간을 적용한 반면에, 대조군에게는 4 주간, 주당 5 회, 회기당 30 분씩 2 회, 총 60 분간 적용하였다. 일반적인 물리치료는 중추신경계 발달 치료(neuro-developmental-treatment, NDT)에 근거한 물리치료 를 의미한다.

\section{5. 자료분석}

본 연구에서 수집된 자료를 분석하기 위해 SPSS Win. 21.0 Package 을 사용하였고 통계적 유의수준은 0.05로 설정하였다. Shapiro-Wilk 검정을 이용하여 정규성 검정을 실시한 결과 정규성이 성립되지 않 아 비모수 통계를 사용하였다. 대상자의 일반적인 특성 및 사전종속 변수의 동질성 검정을 위해 Chi Squared 검정 및 Kruskal Wallis H 검 정을 시행하였다. 각 그룹의 훈련 전. 후 집단 내 종속변수의 변화를 알아보기 위해 Wilcoxon 부호-순위 검정을 이용하여 분석하였다. 또 한 훈련 전. 후 집단 간 종속변수의 변화량을 비교하기 위하여 Krus$\mathrm{kal} \mathrm{Wallis} \mathrm{H}$ 검정을 이용하였고, 사후 검정을 위하여 Mann-Whitney $\mathrm{U}$ 검정을 실시한 후 유의수준은 Bonferroni 수정하여 0.017 ( $\mathrm{p}<0.017$, $0.05 / 3$ )로 정하였다.

Table 1. Exercise components

\begin{tabular}{|c|c|c|}
\hline Week & Exercise components & Exercise duration \\
\hline \multirow[t]{4}{*}{$1-2$} & Standing with your back on a swiss ball & $30 \sec ^{*} 3$ set \\
\hline & Back on the gym ball and alternately up and down feet on the footrest (height $5 \mathrm{~cm}$ ) & 10 times per set ${ }^{\star} 3$ set \\
\hline & Squat with back on the gym ball and knee joint at $30^{\circ}$ flexion. & 10 times per set ${ }^{\star} 3$ set \\
\hline & Standing with the affected side on a swiss ball & $30 \sec ^{*} 3$ set \\
\hline \multirow[t]{4}{*}{$3-4$} & Standing with back on the swiss ball and moving the rings & $30 \sec ^{*} 3$ set \\
\hline & Back on the gym ball and alternately up and down feet on the footrest (height $10 \mathrm{~cm}$ ) & 10 times per set ${ }^{\star} 3$ set \\
\hline & Squat with back on the gym ball and knee joint at $60^{\circ}$ flexion. & 10 times per set ${ }^{\star} 3$ set \\
\hline & Affected side on the swiss ball and up and down non-affected side on the footrest (10 cm in height) & 10 times per set ${ }^{\star} 3$ set \\
\hline
\end{tabular}


결 과

\section{1. 연구대상자의 특성}

연구대상자들의 일반적인 특성은 Table 2 와 같다. 연구대상자들의 성별, 연령, 신장, 체중, MMSE-K, 유병기간 및 편마비측 비율의 모든 일반적인 특성에서 집단 간 유의한 차이가 없는 것으로 나타나 동질 성이 확인되었다 $(\mathrm{p}>0.05)$ (Table 2).

\section{2. 종속변수의 동질성 검정 결과}

훈련 전 무릎관절 폄근의 등척성 근력(Table 3), K-BBS 점수(Table 4),
보행속도, 보행률, 한 발짝 길이(Table 5), K-FES점수(Table 6)에서 집단 간 유의한 차이가 없었다( $\mathrm{p}>0.05)$. 따라서 세 집단의 근력, 균형, 보행 및 낙상효능감에서 동질성이 확인되었다.

\section{3. 훈련 전·후 근력의 변화}

1) 마비측 무릎관절 폄근 근력의 변화

마비측 무릎관절 폄근의 근력에서는 실험군1, 실험군2 및 대조군 은 훈련 전보다 훈련 후에 유의하게 증가하였고 $(\mathrm{p}<0.05)$, 집단 간 마 비측 무릎관절 폄근 근력의 훈련 전·후 변화량은 유의한 차이가 있 었다 $(\mathrm{p}<0.05)$. 사후검정 결과, 마비측 무릎관절 폄근 근력의 변화량

Table 2. General characteristics of subjects

\begin{tabular}{|c|c|c|c|c|c|}
\hline & Experiment Group 1 & Experiment Group 2 & Control Group & $x^{2}$ & $\mathrm{p}$ \\
\hline \multicolumn{6}{|l|}{ Sex } \\
\hline Female/male [n(\%)] & $4 / 3(60 / 40)$ & $3 / 4(40 / 60)$ & $6 / 1(90 / 10)$ & 2.692 & 0.260 \\
\hline Age (yr) & $71.0 \pm 11.0$ & $69.1 \pm 11.0$ & $64.1 \pm 14.5$ & 1.444 & 0.486 \\
\hline Height (cm) & $161.1 \pm 11.0$ & $161.0 \pm 10.2$ & $159.4 \pm 10.1$ & 0.171 & 0.918 \\
\hline Weight (kg) & $61.1 \pm 11.1$ & $61.0 \pm 8.9$ & $58.6 \pm 10.7$ & 0.279 & 0.87 \\
\hline MMSE-K (score) & $26.7 \pm 1.9$ & $26.4 \pm 2.0$ & $27.9 \pm 1.5$ & 2.576 & 0.276 \\
\hline Onset & $3.9 \pm 1.7$ & $4.0 \pm 1.4$ & $3.9 \pm 1.7$ & 0.053 & 0.974 \\
\hline \multicolumn{6}{|l|}{ Affected side } \\
\hline Right/Left [n(\%)] & $4 / 3(60 / 40)$ & $5 / 2(70 / 30)$ & $4 / 3(60 / 40)$ & 0.404 & 0.817 \\
\hline
\end{tabular}

Experiment Group 1: performed various lower extremity exercise using a swiss ball, Experiment Group 2: performed same exercise without swiss ball, Control Group: general physical therapy.

Table 3. Changes in muscle strength before and after training

\begin{tabular}{|c|c|c|c|c|c|}
\hline Variable & Experiment Group $1(n=7)$ & Experiment Group $2(n=7)$ & Control Group $(n=7)$ & $\chi^{2}$ & $P$ \\
\hline \multicolumn{6}{|c|}{ Affected Knee Extensor (Nm) } \\
\hline Pre & $31.76 \pm 6.28$ & $29.23 \pm 6.74$ & $30.37 \pm 3.67$ & 0.356 & 0.837 \\
\hline Post & $35.43 \pm 6.04$ & $32.84 \pm 6.30$ & $31.09 \pm 3.34$ & & \\
\hline Post-Pre & $3.67 \pm 2.14$ & $3.61 \pm 2.38$ & $0.71 \pm 0.51$ & 9.034 & $0.011^{*}$ \\
\hline z & -2.366 & -2.366 & -2.213 & & \\
\hline$p$ & $0.018^{*}$ & $0.018^{*}$ & $0.027^{*}$ & & \\
\hline
\end{tabular}

Mean \pm SD.

Experiment Group 1: performed various lower extremity exercise using a swiss ball, Experiment Group 2: performed same exercise without swiss ball, Control Group: general physical therapy.

${ }^{*} \mathrm{p}<0.05$.

Table 4. Changes in balance before and after training

\begin{tabular}{|c|c|c|c|c|c|}
\hline Variable & Experiment Group $1(n=7)$ & Experiment Group $2(n=7)$ & Control Group $(n=7)$ & $\chi^{2}$ & $\mathrm{p}$ \\
\hline \multicolumn{6}{|l|}{ BBS (Score) } \\
\hline Pre & $35.14 \pm 8.51$ & $32.43 \pm 7.59$ & $39.14 \pm 10.20$ & 1.838 & 0.399 \\
\hline Post & $39.43 \pm 7.98$ & $34.86 \pm 8.03$ & $40.14 \pm 9.70$ & & \\
\hline Post-Pre & $4.29 \pm 1.11$ & $2.42 \pm 1.40$ & $1.00 \pm 0.82$ & 12.221 & $0.002^{*}$ \\
\hline z & -2.379 & -2.392 & -2.07 & & \\
\hline $\mathrm{p}$ & $0.017^{\star}$ & $0.017^{*}$ & $0.038^{*}$ & & \\
\hline
\end{tabular}

Mean \pm SD.

BBS: Berg balance scale, Experiment Group 1: performed various lower extremity exercise using a swiss ball, Experiment Group 2: performed same exercise without swiss ball, Control Group: general physical therapy.

${ }^{*} p<0.05$. 
Table 5. Changes in gait before and after training

\begin{tabular}{|c|c|c|c|c|c|}
\hline Variable & Experiment Group $1(n=7)$ & Experiment Group $2(n=7)$ & Control Group $(n=7)$ & $\chi^{2}$ & $\mathrm{p}$ \\
\hline \multicolumn{6}{|c|}{ Cadence (step/min) } \\
\hline Pre & $96.42 \pm 15.97$ & $93.61 \pm 19.68$ & $97.02 \pm 32.44$ & 0.067 & 0.967 \\
\hline Post & $113.73 \pm 8.89$ & $97.74 \pm 19.76$ & $99.38 \pm 31.49$ & & \\
\hline Post-Pre & $17.31 \pm 10.70$ & $4.37 \pm 2.43$ & $2.36 \pm 2.41$ & 9.944 & $0.007^{*}$ \\
\hline z & -2.366 & -2.197 & -2.366 & & \\
\hline $\mathrm{p}$ & $0.018^{*}$ & $0.028^{*}$ & $0.018^{*}$ & & \\
\hline \multicolumn{6}{|c|}{ Gait speed (m/s) } \\
\hline Pre & $0.50 \pm 0.15$ & $0.63 \pm 0.21$ & $0.75 \pm 0.35$ & 2.203 & 0.332 \\
\hline Post & $0.62 \pm 0.23$ & $0.66 \pm 0.20$ & $0.76 \pm 0.35$ & & \\
\hline Post-Pre & $0.12 \pm 0.09$ & $0.03 \pm 0.06$ & $0.00 \pm 0.04$ & 8.850 & $0.012^{*}$ \\
\hline z & -2.375 & -1.355 & -0.511 & & \\
\hline $\mathrm{p}$ & $0.018^{*}$ & 0.176 & 0.61 & & \\
\hline \multicolumn{6}{|c|}{ NA Step Length (cm) } \\
\hline Pre & $30.91 \pm 11.75$ & $37.37 \pm 7.97$ & $44.01 \pm 12.25$ & 5.662 & 0.059 \\
\hline Post & $34.01 \pm 10.78$ & $38.91 \pm 6.58$ & $43.15 \pm 13.12$ & & \\
\hline Post-Pre & $3.19 \pm 1.77$ & $1.54 \pm 2.82$ & $-0.86 \pm 5.83$ & 3.681 & 0.159 \\
\hline z & -2.366 & -1.521 & -0.169 & & \\
\hline $\mathrm{p}$ & $0.018^{*}$ & 0.128 & 0.866 & & \\
\hline
\end{tabular}

Mean $\pm S D$.

NA: non affected side, Experiment Group 1: performed various lower extremity exercise using a swiss ball, Experiment Group 2: performed same exercise without swiss ball, Control Group: general physical therapy.

${ }^{*} \mathrm{p}<0.05$.

Table 6. Changes in Fall Efficacy before and after training

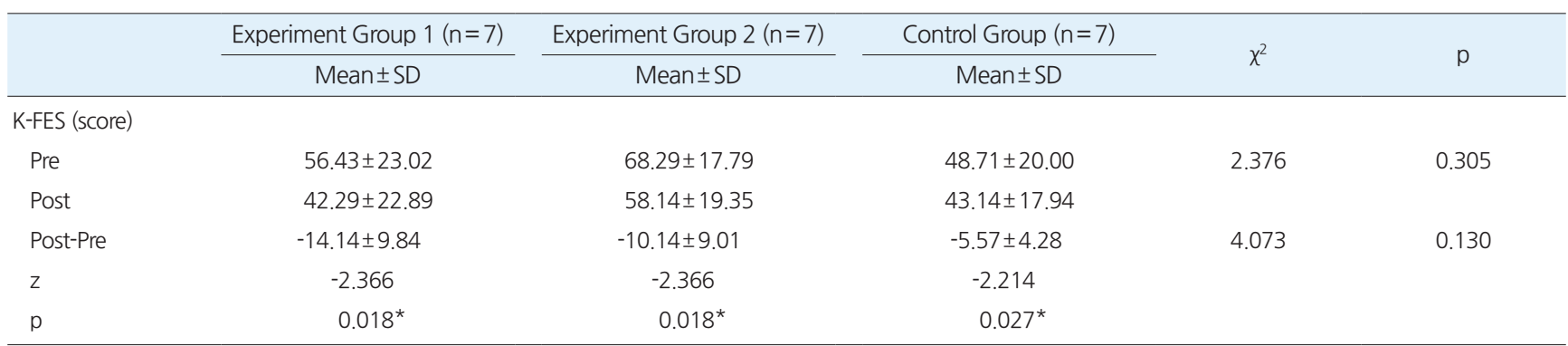

Mean \pm SD.

K-FES: Korean Falls Efficacy Scale, Experiment Group 1: performed various lower extremity exercise using a swiss ball, Experiment Group 2: performed same exercise without swiss ball, Control Group: general physical therapy.

${ }^{*} p<0.05$.

은 실험군1과 실험군2는 대조군보다 유의하게 더 큰 것으로 나타났 다 $(\mathrm{p}<0.017)$ (Table 3$)$.

\section{4. 훈련 전·후 균형의 변화}

BBS점수에서는 실험군1, 실험군2 및 대조군은 훈련 전 보다 훈련 후에 유의하게 증가하였고 $(\mathrm{p}<0.05)$, 집단 간 훈련 전. 후 BBS점수의 변화량은 유의한 차이가 있었다 $(\mathrm{p}<0.05)$. 사후검정 결과, BBS점수에 서 실험군 1 은 대조군보다 유의하게 더 큰 것으로 나타났다 $(\mathrm{p}<0.017)$ (Table 4).

\section{5. 훈련 전·후 보행의 변화}

1) 보행률의 변화

보행률에서는 실험군1, 실험군2, 대조군 모두 훈련 전 보다 훈련 후 에 유의하게 증가하였고 $(\mathrm{p}<0.05)$, 집단 간 보행률의 훈련 전·후 변화 량은 유의한 차이가 있었다 $(\mathrm{p}<0.05)$. 사후검정 결과, 보행률의 변화 량에서 실험군 1 은 대조군보다 유의하게 더 큰 것으로 나타났다 $(\mathrm{p}<$ 0.017) (Table 5).

\section{2) 보행속도의 변화}

보행속도에서는 실험군1은 훈련 전 보다 훈련 후에 유의하게 증가 
하였고 $(\mathrm{p}<0.05)$, 실험군 2 와 대조군에서는 훈련 전보다 훈련 후에 유 의한 차이가 없었다 $(\mathrm{p}>0.05)$. 집단 간 훈련 전. 후 보행속도의 변화량 은 유의한 차이가 있었다 $(\mathrm{p}<0.05)$. 사후검정 결과, 보행속도의 변화 량에서 실험군 1 은 대조군보다 유의하게 더 큰 것으로 나타났다 $(\mathrm{p}<$ 0.017) (Table 5).

\section{3) 한발짝길이의 변화}

비마비측 한 발짝 길이에서는 실험군1은 훈련 전 보다 훈련 후에 유의하게 증가하였으나 $(\mathrm{p}<0.05)$, 실험군2 및 대조군에서는 훈련 전. 후에 유의한 차이가 없었다( $\mathrm{p}>0.05)$. 집단 간 훈련 전. 후 한발짝길이 의 변화량은 유의한 차이가 없었다( $\mathrm{p}>0.05$ ) (Table 5).

\section{6. 훈련 전·후 낙상효능감의 변화}

K-FES 점수에서는 실험군1, 실험군2 및 대조군 모두 훈련 전 보다 훈련 후에 유의하게 감소하였으나 $(\mathrm{p}<0.05)$, 집단 간 훈련 전· 후 K-FES 의 변화량은 유의한 차이가 없었다 $(\mathrm{p}>0.05)$ (Table 6).

\section{고 찰}

본 연구의 목적은 스위스 볼을 이용한 다양한 하지 운동이 뇌졸중 환자의 근력, 균형, 보행 및 낙상효능감에 어떤 영향을 미치는지를 알 아보기 위한 것이었다. 연구의 목적을 달성하기 위해 뇌졸중 환자 21 명을 실험군1, 실험군2 및 대조군에 무작위 배정한 후, 각 집단 별 스 위스볼을 이용한 다양한 하지 운동, 스위스볼을 이용하지 않고 동일 한 운동 및 일반적인 물리치료를 4 주간 적용하였다.

본 연구에서 훈련 전·후 마비측 무릎폄근의 근력을 평가하기 위하 여 휴대용 근력 측정계를 사용하여 측정한 결과, 실험군1, 실험군2, 대 조군의 세 집단 모두 무릎 폄근은 훈련 전보다 훈련 후에 유의하게 증 가하였으며, 실험군1과 실험군2는 대조군보다 마비측 무릎폄근의 근 력이 유의하게 더 크게 증가하였다. 본 연구 결과와 유사하게 $\mathrm{Oh}$ 등 36 의 연구에서 정상 성인에게 수행한 스위스볼을 이용한 스쿼트 운동 군(실험군)이 벽을 이용한 스쿼트 운동군(대조군)보다 넙다리네갈래 근 중 특히 안쪽넓은근과 가쪽넓은근의 활성도가 높게 나타났다. $\mathrm{Oh}$ 등 ${ }^{36}$ 의 연구에서는 1 회의 스쿼트 운동 수행으로 넙다리네갈래근의 활성화를 측정하였는데, 이는 스쿼트 운동을 통해 근력 개선이 가능 할 수 있는 근육으로 생각된다. 본 연구에서는 반복된 운동을 통해 넙다리네갈래근의 근력 증진이 나타났다고 생각된다. Park 등 ${ }^{37}$ 의 연 구에서는 무릎 관절 각도를 다르게 하거나 벽이나 스위스볼을 이용 한 스쿼트 운동 시에 주동근이 되는 무릎 관절 폄근의 근활성도가 주로 높아지는 것을 볼 수 있고 하지 근력 강화에 도움이 되는 운동 으로 다양한 스쿼트 운동이 적용될 수 있을 것이라 하였으며, 이는
본 연구의 연구결과를 뒷받침한다.

본 연구에서 훈련 전·후 균형의 변화를 알아보기 위해 BBS점수를 측정한 결과, 세 집단 모두 훈련 전보다 훈련 후에 $\mathrm{BBS}$ 점수가 유의하 게 증가하였으며, 실험군1은 실험군2 및 대조군보다 유의하게 더 크 게 증가하였다. 본 연구결과와 유사하게 $\mathrm{Bang}^{19}$ 의 연구에서는 뇌졸중 환자들을 대상으로 스위스볼을 이용한 과제 지향 훈련을 8 주간, 주 당 2 회, 50 분 동안 적용한 결과, 균형 능력이 유의하게 향상되는 것으 로 나타났다. 이런 연구결과는 스위스볼 운동이 고유수용성 감각을 자극하여 자세 유지에 필요한 정위반응과 평형반응을 향상시켜 몸 통의 조절과 균형에 긍정적인 영향을 미친 것으로 사료된다.3738

본 연구결과에서 실험군 1 은 훈련 전보다 훈련 후에 보행률, 보행속 도, 비마비측 한발짝길이가 유의하게 증가하였고, 보행률 및 보행속 도 변화량에서 집단 간 유의한 차이가 있었다. 사후 검정 결과, 실험군 1 이 대조군보다 보행률, 보행속도에서 유의하게 더 크게 향상되었고, 실험군1은 실험군2보다 보행률이 더 크게 향상되었다. 본 연구 결과 와 유사하게 Lee 등 ${ }^{39}$ 의 연구에서 편마비환자에게 탄성밴드 및 스위 스 볼 운동을 수행한 결과, 보행속도 및 한발짝길이에서 유의한 향상 이 나타났으며, Lee 등 ${ }^{39}$ 은 스위스볼 운동을 통해 근육의 활성도와 수축 타이밍의 향상으로 나타난 효과이며, 스위스볼을 이용한 신장 운동은 근육의 길이 변화와 속도에 민감하게 반응하는 근방추의 반 응을 높이기 때문에 대부분 하지 근육의 신장성 활성을 일으키는 보 행동작시 근육의 활성도를 증가시킴과 동시에 적절한 수축타이밍을 제공함으로써 인체 분절의 동적 안정성이 향상되었기 때문이라고 하 였다. 또한 불안정 상태에서 동적 안정성을 회복하는 동안 고유수용 기가 자극되고, 균형 유지를 위해 정위와 평형반응이 활성화됨으로 써 신체 균형 유지능력과 보행속도가 향상된 것으로 생각하며, ${ }^{37}$ 한 발짝길이가 증가되었기 때문에 보행속도가 더 크게 향상되었을 것이 고 ${ }^{40}$ 비마비측의 한발짝 길이가 증가된 것은 마비측의 하지에 체중 부하가 증가되어 비마비측 하지의 움직임을 더 허용한 결과라고 생 각된다. ${ }^{41}$

본 연구에서는 훈련 전·후 낙상효능감의 변화를 알아보기 위해 K-FES를 측정한 결과, 세 집단 모두 훈련 전보다 훈련 후에 K-FES 점 수가 유의하게 향상되었으나, 집단 간 K-FES 점수의 변화량에서는 유 의한 차이가 없는 것으로 나타났다. 본 연구결과와 유사하게 Cho 등42 의 연구에 의하면 여성 노인들은 스위스볼과 발란스패드를 사용한 운동을 10 주간, 주당 3 회, 50 분 동안 수행한 결과, 그들의 낙상효능감 이 두 집단에서 모두 유의하게 향상된 것으로 나타났다. Cho 등 ${ }^{42}$ 은 하지 근력 및 균형 향상으로 보행 능력 향상과 심리적 요인인 낙상 공 포에 대한 두려움의 감소에 영향을 미쳤다고 하였다. 이런 결과는 균 형 및 보행이 좋아짐에 따라 낙상에 대한 자신감이 향상된 것으로 생 각되며, K-FES는 낙상에 대한 주관적인 느낌을 측정한 평가도구이기 
때문에 집단 간 훈련 효과를 확인하기 어려웠던 것으로 생각된다.

본 연구의 제한점은 연구대상자가 질병으로 인한 뇌졸중 진단을 받은 지 6개월 이하인 자로 국한되어 있고 대상자 수가 적어 본 연구 결과를 일반화할 수 없다. 따라서 이후 연구에서는 만성 뇌졸중 환자 들을 포함하고 대상자 수를 증가시켜 연구가 이루어져야 할 필요가 있다.

본 연구는 선 자세에서 스위스볼을 이용한 다양한 하지 운동이 뇌 졸중 환자의 근력, 균형, 보행 및 낙상효능감에 어떤 영향을 미치는 지 를 알아보기 위해 예비연구를 시행하였다. 연구결과, 스위스볼을 이 용하여 다양한 하지 운동을 수행한 실험군 1 은 마비측 무릎 폄근 근 력, 버그 균형 척도 점수, 보행률, 보행속도, 한발짝길이 및 낙상효능감 척도 점수가 중재 전보다 중재 후에 유의하게 향상되었다. 실험군 1 은 일반적인 물리치료를 적용한 대조군보다 중재 후 균형, 근력, 보행률 및 보행속도가 유의하게 더 향상되는 것으로 나타났다. 결론적으로 선 자세에서 스위스 볼을 이용한 다양한 하지 운동이 뇌졸중 환자들 의 근력, 균형, 보행 및 낙상효능감을 향상하기 위한 중재가 될 수 있 음을 제안한다.

\section{REFERENCES}

1. M Nabavi S, Daglia M, H Moghaddam A et al. Tea consumption and risk of ischemic stroke: a brief review of the literature. Curr Pharm Biotechno. 2014;15(4):298-303.

2. Hwang BY, Han SD, Lee EJ. Effect of home visiting physical therapy on motor function and ADL in the person with chronic stroke. J Kor Phys Ther. 2003;15(4):319-30.

3. Kim EJ, Hwang BY, Kim JH. The effect of core strength exercises on balance and walking in patients with stroke. J Kor Phys Ther. 2009;21(4): $17-22$.

4. Bleyenheuft C, Bleyenheuft Y, Hanson P et al. Treatment of genu recurvatum in hemiparetic adult patients: a systematic literature review. Ann Phys Rehabil Med. 2010;53(3):189-99.

5. Jørgensen L, Crabtree N, Reeve J et al. Ambulatory level and asymmetrical weight bearing after stroke affects bone loss in the upper and lower part of the femoral neck differently: Bone adaptation after decreased mechanical loading. Bone. 2000;27(5):701-7.

6. Patterson KK, Parafianowicz I, Danells CJ et al. Gait asymmetry in community-ambulating stroke survivors. Arch Phys Med Rehabil. 2008; 89(2):304-10.

7. Chen CL, Chen HC, Tang SFT et al. Gait performance with compensatory adaptations in stroke patients with different degrees of motor recovery. Am J Phys Med Rehabil. 2003;82(12):925-35.

8. Nashner L. Evaluation of postural stability, movement, and control. J Clin Exerc Physiol. 1994:199-234.

9. Dodd KJ, Morris ME. Lateral pelvic displacement during gait: abnormalities after stroke and changes during the first month of rehabilitation. Arch Phys Med Rehabil. 2003;84(8):1200-5.

10. Cikajlo I, Rudolf M, Goljar N et al. Telerehabilitation using virtual reality task can improve balance in patients with stroke. Disabil Rehabil. 2012; 34(1):13-8.

11. Goldie P, Matyas T, Evans O et al. Maximum voluntary weight-bearing by the affected and unaffected legs in standing following stroke. Clin Biomech. 1996;11(6):333-42.

12. Kang YH, No JY. Motor recovery after stroke. J of Korean Acad of Rehab Med. 1995;19(1):55-61.

13. Kim JH, Kim CS. Effects of virtual reality program on standing balance in chronic stroke patients. J Kor Phys Ther. 2005;17(3):351-67.

14. An SH, Park CS. The relationship between postural control, ADL function, muscle tone, and functional improvement in chronic stroke patients. Phys Ther Korea. 2007;14(1):64-73.

15. Karthikbabu S, Nayak A, Vijayakumar K et al. Comparison of physio ball and plinth trunk exercises regimens on trunk control and functional balance in patients with acute stroke: a pilot randomized controlled trial. Clin Rehabil 2011;25(8):709-19.

16. Seo NS, Han MS, Lee JS. Effects of a tilting training program on lower extremities function, depression, and self-efficacy among stroke inpatients. J Korean Acad Nurs. 2006;36(3):514-22.

17. Bagley P, Hudson M, Forster A et al. A randomized trial evaluation of the oswestry standing frame for patients after stroke. Clin Rehabil. 2005;19(4):354-64.

18. Logan A, Freeman J, Kent B et al. Standing practice in rehabilitation early after stroke (spires): a functional standing frame programme (prolonged standing and repeated sit to stand) to improve function and quality of life and reduce neuromuscular impairment in people with severe subacute stroke-a protocol for a feasibility randomised controlled trial. Pilot Feasibility Stud. 2018;4(1):1-18.

19. Bang JH. The effects of theratainment task-oriented swiss ball exercise program on the upper extremity function, balance, and functional selfefficacy in stroke patients. Journal of Korea Entertainment Industry Association. 2016;10(4):93-104.

20. Seo YJ, Oh YS. Effect of swiss ball exercise on trunk ability and postural sway in stroke patients. The Official Journal of the Korean Academy of Kinesiology. 2016;18(2):71-80.

21. Shinde SG, Ganvir SS. Effect of swiss ball training on trunk performance in patients with stroke. Rom J Physical Ther Revista Romana de Kinetoterapie. 2014;20(34):97-101.

22. Han SW, Lee DJ, Lee ES. Effects of trunk muscle strength, coordination and pain after sling and swiss ball exercise for low back pain patients. Journal of Coaching Development. 2014;16(3):123-32.

23. Kim GD, Heo M. Effects of swiss ball exercise program for improvement of life care on balance and gait in local community elderly. Journal of KOEN. 2018;12(7):353-9.

24. Han SW, Cho SY, Kim YS et al. The effect of isometric exercise using swiss ball on the flexibility, the strength and the waist and hip circumferences. J Kor Phys Ther. 2001;13(1):73-82.

25. Mori A. Electromyographic activity of selected trunk muscles during stabilization exercises using a gym ball. Electromyogr Clin Neurophysiol. 2004;44(1):57-64.

26. Muniyar KD, Darade SB. Effect of swiss ball training and conventional physio-therapy to improve balance and mobility in post-stroke patients. Int J Physiother Res. 2018;6(4):2813-22.

27. Bohannon RW. Test-retest reliability of hand-held dynamometry during 
a single session of strength assessment. Phys Ther. 1986;66(2):206-9.

28. Kim YE, Bang DH, Shin WS. Effects of ankle joint position during closed kinetic chain exercise on strength and balance in chronic stroke. J Kor Phys Ther. 2015;27(5):345-50.

29. Berg K, Wood-Dauphinee S, Williams J. The balance scale: Reliability assessment with elderly residents and patients with an acute stroke. Scand J Rehab Med. 1995;27(1):27-36.

30. Blum L, Korner-Bitensky N. Usefulness of the berg balance scale in stroke rehabilitation: a systematic review. Phys Ther. 2008;88(5):559-66.

31. De Ridder R, Lebleu J, Willems T et al. Concurrent validity of a commercial wireless trunk triaxial accelerometer system for gait analysis. J Sport Rehabil. 2019;28(6):1-13.

32. Ahn SH, Shin HH, Cho HY et al. The reliability and validity of the falls efficacy scale (korean version) in stroke patients. J Spec Educ Rehabil Sci. 1990;45(6):239-43.

33. Kim H, Jung MY. Effects of one-to-one fall prevention education on decrease in falls of adults with stroke. Jour of KoCona. 2015;15(5):426-35.

34. Laufer Y, Dickstein R, Resnik S et al. Weight-bearing shifts of hemiparetic and healthy adults upon stepping on stairs of various heights. Clin Rehabil. 2000;14(2):125-9.

35. Gong WT, Lee JN, Park JM. The influence of unstable modified wall squat exercises on the gait variables of healthy adults. J Korean Acad Or- thop Man Physi Ther. 2016;22(1):9-15.

36. Oh TY. The effects of squatting exercise with gym ball and wall on lower extremity muscles activation. J Korean Soc Phys Med. 2013;8(4):647-53.

37. Ko DS, Kim CK, Jung DI. Analysis of spasticity and balance of lower extremity on swiss ball lumbar stabilization exercise (lse) in patients with stroke. Jour of KoCona. 2011;11(3):262-70.

38. Viswaja K, Pappala KP, Tulasi PR et al. Effectiveness of trunk training exercises versus swiss ball exercises for improving sitting balance and gait parameters in acute stroke subjects. Int J Physiother. 2015;2(6):925-32.

39. Lee HJ, Seong RM, Kim BS. The effects of elastic band and swiss ball exercise on the Stroke Patient's muscle strength and walking biomechanical variables. Korean J Sport Sci. 2008;17(4):1387-96.

40. Jin YS, Jeong TG. Effects of neuromuscular electrical stimulation of the vastus medialis on pain and muscle function in patients with knee osteoarthritis. Jour of KoCona. 2012;12(1):329-37.

41. Kim JM, Yi CH, Current ME. A study on the effects of weight-transfer training upon the gait patterns of hemiplegic patients through visual and auditory feedback. Phys Ther Korea. 1995;2(2):9-23.

42. Cho HT, Park YJ, Moo HH. Effect of applied exercise swiss ball and a balance pad maximum strength in the elderly woman lumbar muscle endurance, fear of falling, and physical functions. Journal of Sport and Leisure Studies. 2013;51(2):747-58. 